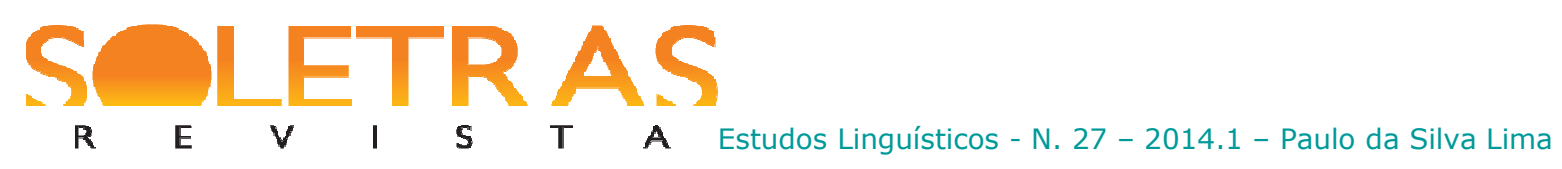

\title{
A correção interativa como mediadora do processo de escrita/reescrita na escola
}

\author{
Paulo da Silva Lima ${ }^{1}$
}

Universidade Federal do Sul e Sudeste do Pará

Resumo: O presente trabalho discute a questão da correção interativa no ensino da produção textual. Nosso objetivo é demonstrar que essa forma de intervenção pode estabelecer um momento de interlocução entre alunos e professores, além de dar aos estudantes orientações sobre as questões micro e macrotextuais que contribuem para uma escrita mais proficiente. Para isso, desenvolvemos uma sequência didática em torno do gênero dissertação escolar, buscando proporcionar uma verdadeira situação de interação verbal. O tema abordado nas dissertações foi a redução da maioridade penal, e no final do projeto os textos foram veiculados dentro e fora do ambiente escolar. Para isso, nos embasamos na teoria textual de Bronckart (2007) e nos estudos de Dolz e Schneuwly (2010) a respeito da didatização de gêneros textuais. Nosso trabalho foi realizado com alunos do Ensino Médio de uma escola pública e nas produções textuais foram analisadas as habilidades linguístico-discursivas apresentadas na primeira e última versão do texto. Assim, constatou-se que a correção interativa conscientiza o educando a respeito da importância da reescrita para uma produção textual mais adequada. Além disso, a intervenção interativa ajudou os educandos a internalizaras principais características e funções sociocomunicativas do gênero dissertação escolar.

Palavras-chave: Correção interativa. Produção textual. Reescrita. Lista de constatações.

\section{Introdução}

O ensino da língua portuguesa tem sido alvo de muitas críticas e isso é notado nos vários trabalhos que fazem referência às dificuldades que os alunos da escola pública encontram para produzir textos dentro de uma situação específica de linguagem. Parte dessa deficiência está associada à maneira como o processo de produção textual é tratado na escola, pois a reescrita, atividade fundamental para que o aluno apreenda meios eficazes de escrita, muitas vezes é desprezada pelo professor. Em muitos casos, isso acontece, segundo Ruiz (2010), porque falta a esses profissionais um conhecimento mais acurado sobre procedimentos teórico-metodológicos capazes de auxiliá-los na preparação de suas práticas pedagógicas.

\footnotetext{
${ }^{1}$ Professor de Linguística e Língua Portuguesa da Universidade Federal do Sul e Sudeste do Pará. Mestre e doutorando em Estudos Linguísticos pela Universidade Presbiteriana Mackenzie. Atua principalmente na área de ensino da língua materna.
} 


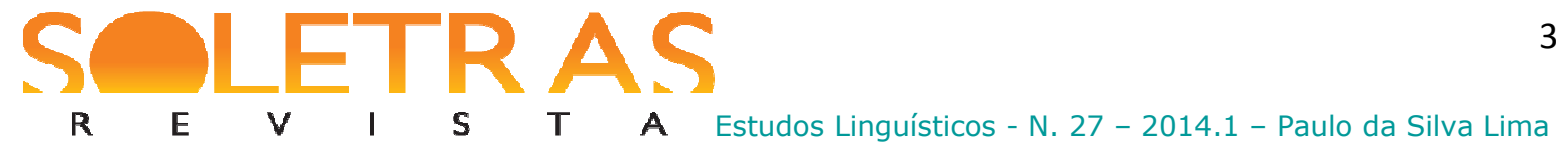

Contrariando a proposta de correção que já se convencionou na escola pública, sendo o papel do professor apenas emitir notas ao texto do aluno, sem haver uma troca de informações capazes de levar o estudante a aperfeiçoar sua escrita, conforme Ruiz (2010), propomos neste trabalho a correção interativa, por meio da "lista de constatações". Assim, utilizando essa outra maneira de corrigir textos, buscamos demonstrar que a correção interativa tem como base a presença de comentários de ordem interlocutiva, que não se prendem a apenas apontar no texto dos alunos os problemas de ortografia, acentuação ou concordância, mas levar o estudante a refletir sobre outros aspectos envolvidos na produção de um texto. Em nosso trabalho, pois, pretendemos, a partir desse procedimento, preencher algumas lacunas deixadas por outras maneiras de intervenção nos textos escolares.

Sendo assim, na primeira parte deste artigo mostramos que a lista de constatações é uma ferramenta didática que auxilia o professor na correção de textos e que, além disso, dá ao aluno as diretrizes essenciais para escrever/reescrever seu texto, levando em consideração as principais características do gênero produzido. Na segunda seção, apresentamos os procedimentos metodológicos da pesquisa, e no terceiro tópico fazemos a análise da primeira e segunda produção de um aluno, tentando evidenciar a função interlocutiva e reguladora da aprendizagem que a lista de constatações desempenha no ensino da produção textual.

\section{A lista de constatações como instrumento regulador da aprendizagem}

Em trabalhos já realizados sobre a produção de textos na escola, pôde-se constatar que muitos docentes estão mais preocupados em corrigir somente os problemas referentes à pontuação, ortografia e concordância, deixando de lado uma avaliação que também abarque o conteúdo proposicional do texto. Assim, como bem aborda Ruiz (2010), a intervenção feita por muitos professores é pautada somente em apontamentos, indicações e comentários de desvios da norma gramatical que em quase nada contribuem para uma melhoria da escrita dos estudantes.

Por isso, é preciso que a avaliação da produção textual seja embasada em formas de intervenção que possam ir além dos problemas microtextuais, e uma das maneiras de fazer isso é adotando a lista de constatações como parâmetro para a produção/correção do texto. Conforme Dolz et alii (2010), uma lista de constatações/controle diz respeito a algumas categorias que serão usadas na análise dos textos dentro da aplicação de uma sequência didática. Além disso, a construção da lista para um determinado gênero deve levar em 
consideração as capacidades de ação, as capacidades discursivas e as capacidades linguísticodiscursivas (BRONCKART, 2007). Por isso, é preciso que o professor conheça bem o gênero a ser utilizado como modelo da produção textual.

Isso mostra que, por meio desse aplicativo didático, não só os problemas superficiais como acentuação, ortografia, pontuação etc. podem ser considerados no momento de correção, mas também os que estão relacionados à adequação do gênero e à construção dos sentidos no texto.

Nesse sentido, uma revisão de ordem interativa, via lista de constatações, pode ser um meio eficaz de corrigir os textos escolares, suprindo assim a lacuna deixada por outras formas de intervenção. Por isso, nessa perspectiva, a reescrita tem papel fundamental, e é necessário que o professor tome a sala de aula também como lugar de interação, onde os alunos escreverão não somente para obter uma nota, mas também para dialogar com um interlocutor de forma verdadeira.

Segundo Gonçalves (2009, p. 237),

A correção interativa, via lista de constatações, pode fornecer importante caminho para o educando operar qualificações com e sobre a linguagem e, consequentemente, melhorar seu domínio das capacidades de ação, discursivas e linguístico-discursivas.

Adotando essa perspectiva, o docente tem condições de intervir no gênero trabalhado e construir, por meio de uma atividade dialógica, uma ressignificação para o texto do aluno.

A lista de constatações é uma ferramenta por meio da qual o professor é levado a interagir com seu aluno de forma escrita e oral a respeito do texto produzido. É um recurso que tem como objetivo sintetizar explicitamente as atividades realizadas no desenvolvimento de uma sequência didática. Além disso, proporciona um trabalho de escrita/reescrita de ordem modular no qual as inadequações apresentadas numa primeira produção são trabalhadas de forma sequenciada.

Também, a lista de constatações pode ser mostrada por meio de partes tiradas dos textos escolares; pode ser elaborada pelos próprios alunos ou pode representar uma grande lista de controle de um determinado gênero de texto construída pela classe de forma geral. Em nosso caso, a lista de constatações foi elaborada em conjunto com os alunos para que assim tivessem mais clareza a respeito das características do gênero e dos critérios que seriam levados em consideração durante a correção dos textos.

Além disso, a lista de constatações, funcionando como reguladora da aprendizagem, permite ao educando fazer uma autocrítica sobre sua própria produção, podendo assim 
$\mathbf{R}$

comparar a sua primeira escrita com as escritas posteriores. Conforme Bain \& Schneuwly (apud GOLÇALVES; BAZARIN, 2009, p. 22): “A lista de controle e sua utilização constituem a base de partida para levar os alunos a uma verdadeira ferramenta psicológica, mais uma vez no sentido vygotskiano do termo, permitindo transformar os processos psíquicos".

Quando utilizada numa atividade de escrita/reescrita modular, a lista de constatações torna-se um instrumento de mediação entre alunos e professores, já que por meio dela ocorre uma interlocução pautada em um vocabulário mais comum para ambas as partes. Isso, pois, evidencia que a correção de um texto deve representar um momento de comunicação e trocas, deixando de ser vista, tanto pelo professor quanto pelo aluno, como uma atividade escolar que serve apenas para o estabelecimento de uma nota. É preciso, além disso, que o texto do aluno seja considerado como uma produção mais significativa para sua aprendizagem.

Assim, em nosso trabalho utilizamos a seguinte lista de constatações como parâmetro para as correções das dissertações:

\begin{tabular}{|l|}
\hline \multicolumn{1}{|c|}{ Lista de constatações para o gênero dissertação escolar } \\
\hline Você passa a ideia de alguém que leu e compreendeu os textos abordados na \\
apresentação da situação? \\
O texto pode ser considerado um exemplar do gênero dissertação escolar? \\
Está adequado aos destinatários múltiplos e ao veículo a ser veiculado/publicado? \\
Você passa a imagem de alguém que defende sua ideia por meio de argumentos bem \\
fundamentados? Mobiliza o esquema argumentativo: premissa/tese, argumentos e \\
conclusão? Elabora contra-argumentos? \\
*s argumentos utilizados são coerentes com o tema? São suficientes para conseguir a \\
adesão dos leitores? Foram hierarquizados corretamente de modo a conseguir o efeito \\
de sentido desejado? \\
* Seu texto apresenta progressão temática, ou seja, há em cada parágrafo uma nova \\
informação relacionada ao tema? \\
Sua subjetividade é expressa sem a utilização de expressões em 1a pessoa (eu acho, eu \\
acredito), de forma que seja garantido a seu discurso mais veracidade, não \\
demonstrando uma opinião particular? \\
A coesão do texto é feita por meio de organizadores lógicos, estabelecendo relações \\
sintático-semânticas de causa, consequência, conclusão, concessão etc.? Ou preferiu \\
não utilizar alguns desses elementos, mas como isso há as relaçôes lógico- \\
argumentativas? \\
Evita repetições desnecessárias por meio da coesão nominal (anáforas nominais e \\
pronominais, referenciação dêitica como: este, esse, esta, essa, isto, isso, etc.)? \\
Existem desvios gramaticais em relação à pontuação, frases incompletas/truncadas, \\
ortografia, concordância, etc.?
\end{tabular}




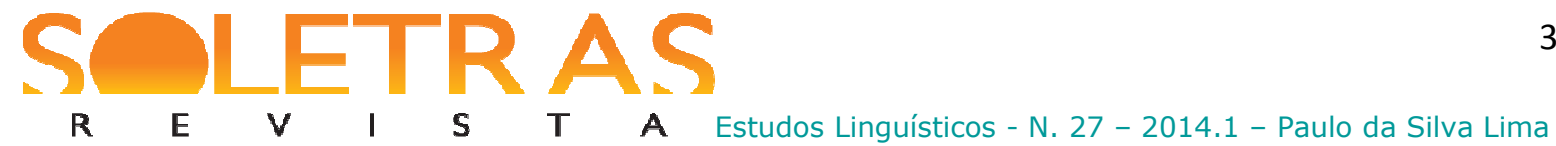

\section{Procedimentos metodológicos da pesquisa}

Para a realização de nosso trabalho, adotamos uma pesquisa qualitativa, cuja denominação é pesquisa-ação, de natureza social empírica e responsável pela resolução de um problema coletivo. Neste caso, o pesquisador deve participar de forma colaborativa, averiguando uma ação problemática que realmente careça de uma investigação.

Para Morin (2004), o objetivo da pesquisa-ação é fazer a comparação de informações, avaliando e discutindo resultados e elaborando generalizações. Nesse tipo de pesquisa, os participantes não devem ser vistos como meras cobaias, mas devem desempenhar papel ativo (em nosso caso, produzir textos). Nesse sentido, o importante não é somente adquirir conhecimentos sobre a questão, mas obter experiências capazes de contribuir para a discussão do problema ou avançar o debate.

Ainda segundo Morin (2004, p. 56), a pesquisa-ação permite aos atores a construção de teorias e estratégias que emergem do campo e que, em seguida, são validadas, confrontadas, desafiadas dentro do campo e acarretam mudanças desejáveis para resolver ou questionar melhor uma problemática. Assim, a reescrita sendo mediada por meio da lista de constatações/controle surgirá da prática de sala de aula para se tornar um método eficiente na produção textual dos alunos.

Em nossa pesquisa, desenvolvemos uma sequência didática, durante 10 aulas, em torno do gênero dissertação escolar, com 30 alunos do $3^{\circ}$ ano do Ensino Médio de uma escola pública de Marabá, PA. O tema escolhido foi a redução da maioridade penal no Brasil e o objetivo da produção foi veicular tais textos no mural da escola, visando não só o professor como leitor, mas toda a comunidade escolar. A sequência didática teve uma duração de 18 horas/aulas. Durante o desenvolvimento do trabalho, tivemos como fator determinante a reescrita sendo mediada pela lista de constatações/controle e pela correção interativa. No entanto, por questões de espaço, apresentaremos apenas a produção inicial e a final de um dos alunos envolvidos na pesquisa.

\section{A correção interativa no processo de escrita/reescrita na escola}

Depois de termos feito a primeira etapa da sequência didática, ou seja, discutido sobre a temática, características do gênero, papel social do produtor e dos leitores visados, pedimos aos alunos que escrevessem a primeira versão de seu texto. Em seguida, com base na lista de 


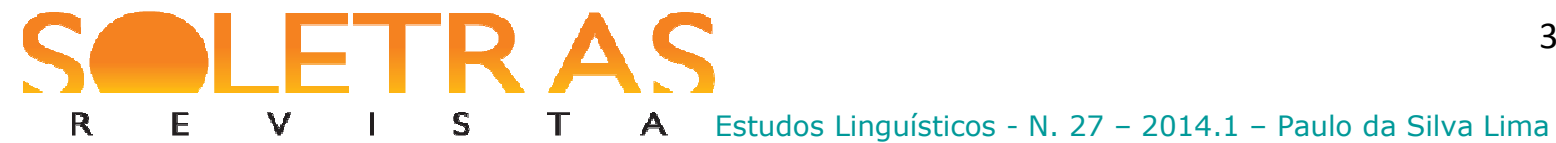

constatações, corrigimos as dissertações, procurando mostrar aos estudantes as questões linguístico-discursivas que estavam adequadas e as que estavam inadequadas para a situação de linguagem. Nas aulas seguintes, procuramos trabalhar as principais dificuldades que foram apresentadas na primeira produção. Depois disso, pedimos aos alunos que reescrevessem seu texto e, após a correção e discussão sobre o que estava adequado e inadequado nas produções, demos continuidade às atividades dos módulos, abordando as dificuldades dos alunos. No final desse processo, os estudantes escreveram a versão final de seu texto, que foi exposta no mural da escola e no blog da Faculdade de Estudos da Linguagem.

Para efeito de demonstrar como foi desenvolvida a correção interativa, exporemos a análise da $1^{\mathrm{a}}$ versão do aluno A1. Assim, serão analisadas as capacidades de ação (contexto de produção), capacidades discursivas (planificação do texto) e as capacidades linguísticodiscursivas (mecanismos de textualização e mecanismos enunciativos).

\begin{tabular}{|c|c|}
\hline & "Jovens de hoje, sociedade futura" \\
\hline & No Brasil está ocorrendo uma polêmica sobre a lei que reduz a maioridade penal, \\
onde os indivíduos infratores com mais de 16 anos, ao invés de 18, assumam as \\
consequências de seus atos; sobretudo para que ocorra a aprovação desta lei esta havendo \\
várias análises de autoridades conforme mostra um vídeo em que a senadora Ana Rita do \\
PT/ES se diz contra a lei uma vez que não é a melhor solução para acabar com a violência \\
entre os jovens. \\
Segundo a ONU de 57 países apenas 10 tem esta lei em vigor os outros atribuem \\
medidas distintas. \\
Mas o que falar quando são notificado casos como o de Emili de 16 anos morta por \\
umenina de 14 anos por causa de um garoto? \\
Vale dizer que já vimos envolvimentos de menores em crimes cruéis onde são usados \\
como laranjas e logo se tornam pequenos traficantes. \\
Contudo sabemos que as penitenciárias estão superlotadas e que não há citação da \\
construção de novas ou a formação de policiais. \\
Em síntese o governo deve se estruturar e seguir o exemplo de vários países \\
assumindo assim um pulso firme na execução desta lei que não vai apenas solucionar a \\
violência entre jovens mas também garantir direitos aos jovens como a habilitação.
\end{tabular}




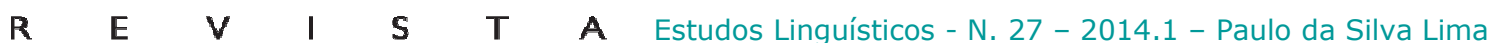

\begin{tabular}{|l|l|l|}
\hline & $>$ & Consegue passar a imagem de alguém que é conhecedor do conteúdo temático; \\
& $>$ O texto é um exemplar do gênero; \\
& Sua dissertação está adequada a destinatários múltiplos; \\
& Passa a imagem de quem argumenta com propriedade, mobilizando o esquema \\
& argumentativo. No entanto, a introdução não está bem demarcada; \\
& $>$ Os argumentos são pertinentes para a adesão do leitor, mas poderia ter exposto outros \\
& mais importantes;
\end{tabular}

Nesse primeiro texto, no contexto sócio subjetivo, o aluno desempenha um papel social de alguém que apresenta seu ponto de vista, visando conseguir a adesão de seu interlocutor em relação à diminuição da maioridade penal no Brasil. O leitor, nesse contexto sócio subjetivo, é formado pelo professor, colegas da sala e comunidade escolar em geral.

Com relação ao conteúdo temático, percebe-se que o aluno-produtor traz para seu texto conhecimentos debatidos durante as aulas que antecederam a primeira produção, como é o caso quando faz referência ao vídeo que traz a opinião da senadora e dos dados da ONU a respeito do assunto. Além disso, defende sua tese por meio de argumentos oriundos de seu conhecimento de mundo.

No que se refere à planificação do texto, o aluno escreve sua dissertação de acordo com o modelo tradicional do gênero, ou seja, introdução, desenvolvimento e conclusão. A progressão temática é estabelecida por meio do encadeamento lógico-argumentativo, sendo uma ideia concatenada à seguinte e garantindo com isso a sequenciação do texto. Assim, no primeiro parágrafo, o agente apresenta sua tese, afirmando que no Brasil está ocorrendo uma polêmica a respeito da lei que poderá reduzir a maioridade penal dos 18 para os 16 anos. No entanto, a introdução não fica bem demarcada e parece confusa, pois nesse mesmo parágrafo já é introduzida a opinião de uma senadora em relação ao assunto.

No segundo parágrafo, dando continuidade à linha argumentativa contrária à redução da maioridade penal, iniciada no final do parágrafo anterior, o autor traz dados da ONU que 
mostram ser pequeno o número de países que aderiram à redução da maioridade. No terceiro, a orientação argumentativa do autor mostra-se a favor da redução e, para isso, cita um fato em que uma adolescente de 14 anos assassinou uma outra por motivo banal. No quarto, menciona que muitos menores estão cometendo crimes cruéis e se tornando traficantes devido a uma impunidade nessa faixa etária.

No quinto parágrafo, o autor problematiza a possibilidade de se reduzir a maioridade penal, já que há uma superlotação das penitenciárias e não existem propostas para a construção de novas casas de detenção e para a contratação de mais policiais. No último parágrafo, o autor dá uma proposta à solução do problema, afirmando que o governo deve seguir o exemplo de outros países e aderir à redução da maioridade. Além disso, deixa a entender que o governo deve garantir direitos aos menores, entre eles a carteira nacional de habilitação.

Há também na planificação textual uma predominância de sequências argumentativas e as unidades linguísticas são autônomas, ou seja, não se referem aos parâmetros da situação de linguagem. Com isso, não há índices linguísticos fazendo referência ao produtor, leitores e nem ao espaço-tempo da produção. Observa-se ainda que o autor utiliza um estilo de linguagem com predominância da norma culta.

Verifica-se também que há a presença de frases declarativas, construção sintática que segundo Souza (2007) é uma marca de gêneros argumentativos. Isso pode ser notado em: No Brasil está ocorrendo (linha 1)/ apenas 10 tem esta lei (linha 7)/ são usados como laranjas (linhas 11-12). Conforme afirmam Vilela \& Koch (2001), no texto argumentativo também são usadas frases interrogativas com valor retórico, induzindo o leitor a uma orientação argumentativa do discurso. Isso, pois, é identificado nesse primeiro texto em: Mas o que falar quando são notificados casos como o de Emili de 16 anos morta por uma menina de 14 anos por causa de um garoto? (linhas 9-10). Por meio dessas construções, o autor problematiza a questão tentando levar o leitor a refletir sobre o assunto.

$\mathrm{O}$ autor usa formas verbais na primeira pessoa do plural, sem fazer referência direta a si e a seus parceiros na interação. Nesse caso, cria-se um efeito de sentido em que o nós representa os participantes da interação verbal em geral, como se vê em: já vimos envolvimentos (linha 11) / sabemos que as penitenciárias (linha 13).

No que diz respeito aos mecanismos de textualização, há no texto a presença de anáforas, entre elas as nominais (a lei/ novas/ jovens), anáforas pronominais (seus atos/ desta lei/ esta lei/ desta lei) e as anáforas decorrentes de elipses (assumam/ são usados). Existem 
operadores textuais com valor lógico-argumentativo que guiam o leitor e organizam o discurso, além de estabelecerem relações entre as frases e os parágrafos. Isso é notado com o uso do que como conjunção integrante: "Vale dizer que já vimos / e que não há citação" (linhas 11 e 13), o uso de operadores com função oposição de ideias: "ao invés de 18/ Mas o que falar quando é notificado casos como o de Emili de 16 anos/ Contudo sabemos que as penitenciárias estão superlotadas" (linhas 2, 9 e 13). O agente-produtor utiliza também, na construção de seu discurso, operadores com função de finalidade: "sobretudo para que ocorra a aprovação desta lei esta havendo" (linha 3), de conformidade: "conforme mostra um vídeo em que a senadora Ana Rita do PT/ES / Segundo a ONU de 57 países apenas 10 tem esta lei em vigor" (linhas 4 e 7), de adição de ideias: "e que não há citação da construção de novas" (linha 13), de conclusão: "Em síntese o governo deve se estruturar" (linha 15), entre outros.

Com relação aos mecanismos enunciativos, verifica-se a presença de modalização lógica, avaliando elementos do conteúdo temático com base em conhecimentos dentro do mundo objetivo: "Vale dizer que já vimos envolvimentos de menores em crimes cruéis" (linha 11) e modalização deôntica, avaliando elementos do conteúdo temático, com base nas regras constitutivas do mundo social: "Em síntese o governo deve se estruturar e seguir o exemplo" (linha 15).

O aluno-produtor traz vozes enunciativas para seu texto no intuito de fazer ponderações mais propícias para conseguir a adesão do leitor. Por isso, vemos a inserção da voz das autoridades em geral: "para que ocorra a aprovação desta lei está havendo várias análises de autoridades" (linhas 3 e 4), de uma senadora: "a senadora Ana Rita do PT/ES se diz contra a lei" (linhas 4-5), a voz da ONU: "segundo a ONU de 57 países apenas 10 tem esta lei" (linha 7). Há também a voz do próprio autor fazendo avaliações de aspectos do que é enunciado: "Vale dizer que já vimos envolvimento de menores" (linha 11) / "Contudo, sabemos que as penitenciárias estão super lotadas" (linha 13).

Os problemas microtextuais, ou seja, aqueles de ordem superficial, foram analisados no último item da lista de controle, destinado aos problemas mais superficiais do texto. Assim, na dissertação em análise, identificamos problemas de uso da vírgula: "sobretudo para que ocorra a aprovação desta lei esta havendo" (linha 3) / "se diz contra a lei uma vez que não é a melhor solução" (linha 5) / "Contudo sabemos" (linha 13) / "Em síntese o governo" (linha 15), de concordância verbal: "o que falar quando são notificados casos como" (linha 9).

Depois de termos feito as considerações sobre a versão inicial, passaremos à análise da produção final do aluno A1. 


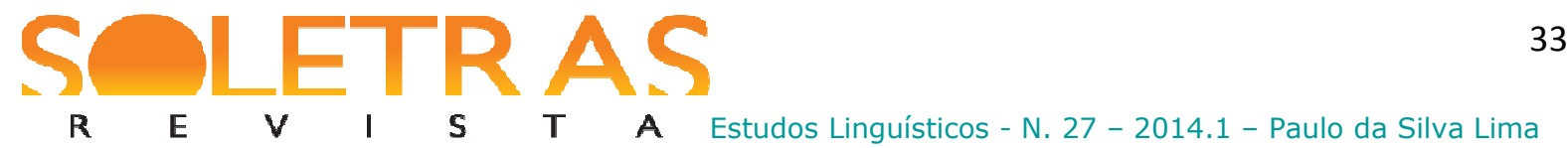

\begin{tabular}{|c|c|}
\hline & "Jovens de hoje, sociedade futura" \\
\hline & No Brasil está ocorrendo uma polêmica sobre a lei que reduz a maioriodade penal \\
em que indivíduos infratores a partir de 16 anos, ao invés de 18, assumam as \\
consequências de seus atos. \\
Sendo assim, para que ocorra a aprovação desta lei está havendo várias análises de \\
autoridades, conforme mostra o vídeo em que a senadora Ana Rita do PT/ES se \\
posiciona contra ao dizer que: "esta não é a melhor solução para acabar com a violência". \\
Segundo a ONU, de 57 países apenas 10 têm esta lei em vigor, os outros atribuem \\
medidas distintas. \\
Mas o que falar quando são notificados casos como o de Emili de 16 anos morta por \\
uma menina de apenas 14 anos por causa de um garoto? \\
Vale dizer que já vimos envolvimentos de menores em crimes cruéis que são usados \\
como laranjas e logo se tornam pequenos traficantes. \\
Contudo, sabemos que as penitenciárias estão super lotadas e que não há citação da \\
construção de novas ou a formação técnica de policiais. \\
Por outro lado, quando pensamos nas famílias que sofrem com a perda de seus \\
jovens para a violência, na precária estrutura escolar pública, percebemos que também se \\
precisa investir em educação com urgência dando mais oportunidades àqueles que ficam \\
a margem da sociedade. \\
Em síntese, o governo deve se estruturar e seguir o exemplo de muitos países \\
assumindo assim um pulso firme na execução desta lei que não vai apenas solucionar a \\
violência, mas também garantir direitos aos jovens como a habilitação.
\end{tabular}

$\mathrm{Na}$ versão final de seu texto, o aluno demonstra estar mais consciente em relação ao contexto de produção. Por isso, no papel de enunciador, dá seu ponto de vista sobre a redução da maioridade penal, pretendendo mostrar que escreveu um texto de acordo com o propósito comunicativo. 


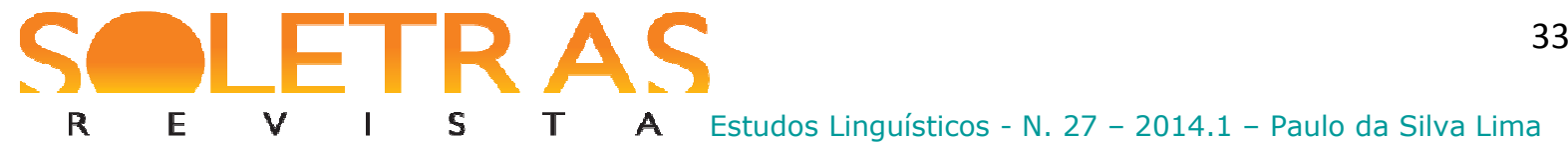

Por isso, nessa versão final, o estudante ampliou sua proficiência no que tange ao conteúdo temático, escrevendo mais um parágrafo para contra-argumentar e fazer avaliação sobre possíveis medidas que o governo pode tomar para diminuir a criminalidade na infância/adolescência.

Analisando-se as capacidades discursivas, verifica-se que no texto final, assim como no primeiro, o tema é desenvolvido por meio de argumentos fundamentados no que foi visto durante as aulas e em outros internalizados pelo aluno de acordo com sua visão de mundo. A progressão temática é estabelecida por meio de um raciocínio lógico/encadeamento de ideias e não há elementos linguísticos que se referem diretamente aos participantes da interação verbal (agente-produtor e leitores) e ao momento de produção, como elementos que indiquem o tempo-espaço da interação.

A dissertação é estruturada no modelo clássico do gênero, apresentando introdução, desenvolvimento e conclusão. Diferentemente do que aconteceu no primeiro texto, que foi escrito em seis parágrafos e com uma introdução não bem demarcada, a versão final apresenta-se em oito parágrafos. Assim, há, no primeiro parágrafo, uma introdução bem demarcada, deixando clara a tese a ser defendida.

Fazendo uma comparação, observa-se que na versão final o agente-produtor seguiu a mesma linha argumentativa do primeiro texto, mas procurou estruturar melhor sua argumentação. Por isso, colocou no segundo parágrafo parte do conteúdo que estava no primeiro e que fazia parte da introdução. Além disso, inseriu mais um parágrafo com o objetivo de preparar a conclusão do texto.

Assim como no primeiro, predominam frases declarativas e frases formadas com o verbo ser no presente com valor atemporal. Há também o uso da primeira pessoa do plural referindo-se aos participantes da interação verbal em geral: "já vimos envolvimentos" (linha 11)/ "sabemos que" (linha 13)/ "quando pensamos nas famílias" (linha 15)/ "percebemos que" (linha 16), sem que isso represente a voz do autor empírico do texto.

No plano das capacidades linguístico-discursivas pôde-se constatar que, nesse segundo texto, por ser uma reescrita bem próxima da primeira versão, apresenta os mesmos mecanismos para fazer a relação lógico-argumentativa e guiar a organização do discurso. No entanto, por haver o acréscimo de dois parágrafos nesse segundo texto, o autor usa outros operadores lógicos como: "Sendo assim, para que ocorra a aprovação desta lei”" (linha 4), introduzindo uma conclusão relacionada a argumentos apresentados anteriormente: "Por outro lado, quando pensamos nas famílias que sofrem" (linha 15), contrapondo argumentos 
voltados para conclusões contrárias; utiliza o operador quando indicando uma circunstância de tempo: "o que falar quando são notificados casos como o de Emili" (linha 9)/ "quando pensamos nas famílias que sofrem" (linha 15). Além disso, faz uso do operador também, somando argumentos a favor de uma mesma conclusão em: "percebemos que também se precisa investir em educação" (linha 16).

Assim como na primeira versão, na segunda há o uso de anáforas nominais e pronominais garantindo o processo de referenciação; há o uso de modalização deôntica com a finalidade de avaliar um elemento do conteúdo temático com base em valores e regras que constituem o mundo social, indicando as medidas que o governo brasileiro deve tomar em relação ao problema: o governo deve se estruturar (linha 19). Diferentemente do primeiro, nesse segundo texto o autor faz a inserção de uma modalização lógica que, segundo Bronckart (2007), tem o objetivo de avaliar elementos do conteúdo temático com base no mundo objetivo, sendo os elementos considerados como fatos possíveis, prováveis e necessários: "também se precisa investir em educação" (linhas 16-17).

Com relação às vozes enunciativas, verifica-se que no texto final, além da voz da senadora, no segundo parágrafo, da voz do autor, no quinto e no sexto, como já havia aparecido no primeiro texto, há também a presença da voz do autor no sétimo parágrafo, comentando aspectos do que é enunciado: "percebemos que” (linha 16).

No segundo texto, verifica-se que o autor levou em consideração o que foi posto como inadequado no primeiro texto por meio da lista de constatações. Por isso, procurou rever os problemas relacionados ao uso de onde com função lógica/encadeamento de ideias. Assim, os trechos: "onde os indivíduos / onde são usados" foram substituídos por: "em que indivíduos" (linha 2) / "em que são usados" ( linha 11). Um problema de referenciação com o uso excessivo de jovens em: "não vai apenas solucionar a violência entre jovens mas também garantir direito aos jovens como a habilitação" (linhas 16-17) foi sanado com: "não vai apenas solucionar a violência, mas também garantir direitos aos jovens" (linhas 20-21).

Além disso, os problemas de acentuação e de concordância verbal que apareceram em: "esta havendo" (linha 3) / "quando é notificado" (linha 9) foram corrigidos em: "está havendo" (linha 4) / "quando são notificados" (linha 9). Inadequações que apareceram no uso da vírgula também foram reparadas na versão final, como, por exemplo, em: "Segundo a ONU, de 57 países" (linha 7) / "Em síntese, o governo deve" (linha 19) / "não vai apenas solucionar a violência, mas também garantir" (linha 21). 


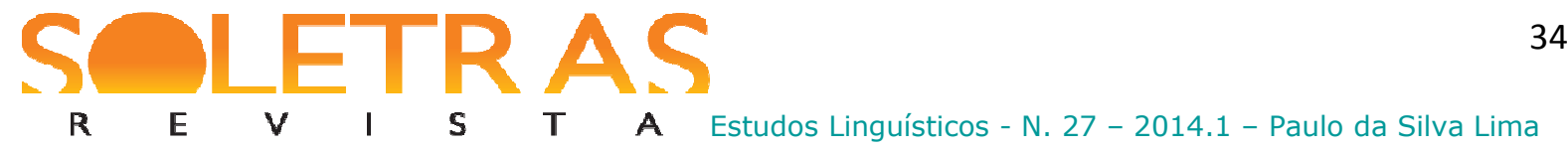

A frase truncada que aparecia no primeiro parágrafo da produção inicial, devido ao uso inadequado do operador "sobretudo" (linha 3), foi corrigida no texto final, pois o autor dividiu o parágrafo em dois e iniciou o segundo por meio do organizador "Sendo assim" (linha 4). Com isso, o agente-produtor também demarcou com mais clareza a introdução, dando ao texto um caráter mais proficiente em relação à planificação.

Como visto nessa breve análise dos dois textos, a correção interativa, por meio da lista de constatações, proporcionou ao estudante uma escrita mais proficiente do gênero. Isso ocorreu porque as observações feitas na primeira correção deram ao aluno o suporte para que este revisasse seu texto e procurasse rever seus erros, preparando-se para a reescrita. Verificou-se também que as atividades desenvolvidas ao longo dos módulos ajudaram o agente-produtor a aprofundar alguns conhecimentos em relação às capacidades de linguagem ligadas ao conteúdo temático, ao plano discursivo e às operações linguístico-discursivas do gênero proposto.

\section{Considerações finais}

Diante do que foi discutido em nosso trabalho, pode-se notar a importância da correção interativa via lista de constatações como um meio essencial para o professor fazer a intervenção no texto do aluno, visto que, dessa forma, o docente tem condições de demonstrar, de forma interativa, em quais aspectos os alunos já estão qualificados e em quais precisam melhorar na escrita/reescrita de seu texto.

Portanto, acreditamos que a correção interativa, via lista de constatações, é um instrumento capaz de auxiliar professores de língua na busca por caminhos que os levem a alcançar os objetivos desejados no que diz respeito ao ensino da produção textual. Além disso, esse instrumento de avaliação pode contribuir para que muitos dos alunos que terminam o Ensino Médio sejam capazes de produzir textos (orais ou escritos) de forma proficiente tanto nos exames que podem proporcionar seu ingresso no mundo do trabalho e no ensino superior quanto em outras situações de práticas de linguagem.

\section{Referências bibliográficas:}

BRONCKART, Jean-Paul. Atividade de linguagem, textos e discursos: por um interacionismo sociodiscursivo. São Paulo: EDUC, 2007.

DOLZ, J. et al.. Sequências didáticas para o oral e a escrita: apresentação de um procedimento. In: SCHNEUWLY, Bernard; DOLZ, Joaquim (Orgs.). Gêneros orais e 


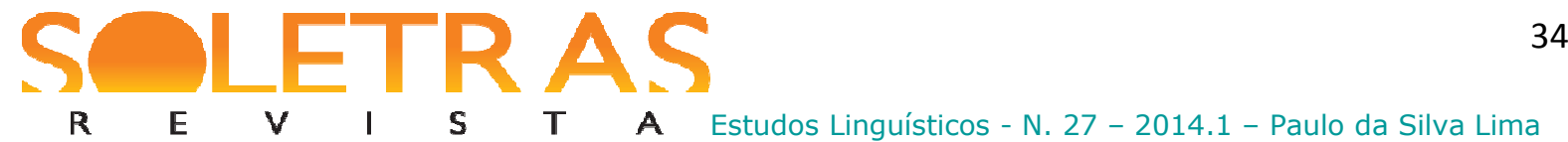

escritos na escola. Trad. Roxane Rojo e Glaís Sales Cordeiro. Campinas, SP: Mercado de Letras, 2010.

GONÇALVES, A. V. Ferramentas didáticas e ensino: da teoria à prática de sala de aula. In: NASCIMENTO, Elvira Lopes (Org.) Gêneros textuais: da didática das línguas aos objetos de ensino. São Carlos, SP: Claraluz, 2009.

GONÇALVES, A. V. \& BARAZRIM, M. (Orgs). Interação, gêneros e letramento: a (re) escrita em foco., São Carlos, SP: Claraluz, 2009.

MORIN, A. Pesquisa-ação integral e sistêmica: uma antropedagogia renovada. Trad. de Michel Thiollent. Rio de Janeiro: DP \& A, 2004.

RUIZ, E. Como corrigir redações na escola. São Paulo: Contexto, 2010.

SCHNEUWLY, Bernard. Gêneros e tipos de discurso: considerações psicológicas e ontogenéticas. In: SCHNEUWLY, Bernard; DOLZ, Joaquim. Gêneros orais e escritos na escola. Campinas, SP: Mercado das Letras, 2010.

SOUZA, E. G. Dissertação: gênero ou tipo textual? In: DIONISIO, A. P.; BESERRA, N. S. (Org.) Tecendo textos, construindo experiências. Rio de Janeiro: Lucerna, 2007.

VILELA, M. \& KOCH, I.V. Gramática da língua portuguesa: gramática da palavra, gramática da frase, gramática do texto/discurso. Coimbra: Almedina, 2001.

\title{
The interactive correction as a mediator of the writing / rewriting process at school
}

\begin{abstract}
This paper discusses the interactive correction in teaching text production. We aim at demonstrating that this form of intervention in textbooks can establish a dialogue between students and teachers, guiding students on the general issues of the texts. Therefore, we developed an instructional sequence on school dissertations to provide this genre with a real situation of interaction. The theme of these dissertations was the age of criminal responsibility of minors. At the end of the project, the texts were made available inside and outside the school environment. We focused our work in the textual theory of Bronckart (2007) and in the studies of Dolz and Schneuwly (2010) regarding the didactization of textual genres. We aimed at high school students in a public school, where we analyzed theit linguistic and discursive skills. Thus, in this article we only use the text of a student in order to demonstrate the evolution between the first and last textual production. Furthermore, we wil state that the interactive intervention helps learners to internalize the key features and the communicative functions of the genre.
\end{abstract}

Key words: Interactive correction. Textual production. Rewriting. List of findings.

Recebido em: 15 de novembro de 2013.

Aprovado em: 18 de novembro de 2013. 